\title{
CUSTOS DA IRRIGAÇÃO E RECEITA LÍQUIDA DO FEIJOEIRO EM UM SISTEMA PIVÔ CENTRAL SOB VARIAÇÃO DO COMPRIMENTO DA TUBULAÇÃO DE RECALQUE E DESNÍVEL TOPOGRÁFICO
}

\author{
JÚLIO S. DE OLIVEIRA ${ }^{1}$, JOÃO L. ZOCOLER ${ }^{2}$
}

\begin{abstract}
RESUMO: Neste trabalho, foi simulado o custo da irrigação de um sistema tipo pivô central com diferentes comprimentos da tubulação de recalque e desníveis topográficos na produção do feijoeiro comum, na região de Ilha Solteira - SP, bem como sua receita líquida. Considerou-se uma área irrigada pelo equipamento de 103,58 ha, sendo sua configuração a mais econômica possível para as variáveis consideradas. A participação da irrigação no custo de produção do feijoeiro variou de 14,8 a $21,5 \%$ entre as condições extremas, ou seja, do menor desnível topográfico (40 m) e comprimento da tubulação de recalque $(2.000 \mathrm{~m})$ ao maior desnível $(80 \mathrm{~m})$ e comprimento $(3.000 \mathrm{~m})$. Em todas as configurações do sistema de irrigação e com os preços praticados em agosto de 2008 ou com o preço histórico médio, seria viável a cultura do feijoeiro, proporcionando rendas líquidas de até $\mathrm{R} \$ 3.959,64 \mathrm{ha}^{-1}$ e até $\mathrm{R} \$ 1.203,14 \mathrm{ha}^{-1}$, respectivamente.
\end{abstract}

PALAVRAS-CHAVE: pivô central, feijoeiro, custos e lucros.

\section{BEAN COST OF IRRIGATION AND PROFIT IN A CENTER PIVOT SYSTEM UNDER VARIATION OF PRESSURIZED PIPE LENGTH AND TOPOGRAPHIC LEVELS}

\begin{abstract}
In this study it was simulated the cost of irrigation by a center pivot system under different pressurized pipe length and topographic levels in the brown bean growing, as well its profit. It was considered an irrigated area of 103.58 ha, being set the most economic system configuration from the considered variables. The cost of irrigation in brown bean growing ranged from 14.8 to $21.5 \%$ between the extreme conditions, in the lower topographic level $(40 \mathrm{~m})$ and pressurized pipe length $(2,000 \mathrm{~m})$ to the largest topographic level $(80 \mathrm{~m})$ and length $(3,000 \mathrm{~m}) . \mathrm{In}$ all irrigation system settings and with prices in August 2008 or the average historic price it would be viable the brown bean growing, providing profits until $\mathrm{R} \$ 3,959.64$ and $\mathrm{R} \$ 1,203.14 \mathrm{ha}^{-1}$, respectively.
\end{abstract}

KEYWORDS: center pivot, bean, costs and profits.

\section{INTRODUÇÃO}

O Brasil é o maior produtor mundial de feijão, sendo responsável por 23,6\% da produção, sendo o Estado do Paraná o maior produtor nacional, com aproximadamente $21 \%$ de toda a produção interna (Companhia Nacional de Abastecimento - CONAB, 2009). Mesmo com o aumento de $48 \%$ na produtividade, obtido nos últimos 17 anos, a redução na área plantada - da ordem de $35 \%$ no mesmo período - provocou diminuição de $4 \%$ na produção brasileira de feijão (YOKOYAMA, 2003). Segundo a Companhia Nacional de Abastecimento - CONAB (2009), a área plantada com feijão no Brasil, na de safra 2007/2008, foi de 3.993 .000 ha, na qual foi obtida uma produção de $3.520 .900 \mathrm{t}$, ou seja, obteve-se uma produtividade de apenas $882 \mathrm{~kg} / \mathrm{ha}(14,7$ sacas de $60 \mathrm{~kg}$ por ha). Basicamente, são três as safras de feijão no Brasil: a $1^{\underline{a}}$ safra (de verão), cuja colheita se concentra nos meses de dezembro a fevereiro nas regiões Centro-Sul e de fevereiro a abril nas

\footnotetext{
${ }^{1}$ Eng. Agrônomo, formado na Faculdade de Engenharia - Campus de Ilha Solteira/UNESP; e-mail: eajsoliveira@gmail.com.

${ }^{2}$ Prof. Adjunto - Departamento de Fitossanidade, Engenharia Rural e Solos - Faculdade de Engenharia - Campus de Ilha

Solteira/UNESP; e-mail: zocoler@agr.feis.unesp.br.

Recebido pelo Conselho Editorial em: 7-12-2010

Aprovado pelo Conselho Editorial em: 16-9-2012
} 
regiões Norte e Nordeste; a $2^{\mathrm{a}}$ safra (safrinha), cuja colheita se concentra nos meses de março e abril; e a $3^{\underline{a}}$ safra (inverno), cuja colheita se concentra nos meses de julho a outubro.

De acordo com CASER et al. (2008), no Estado de São Paulo, na safra de 2007/2008, a área plantada com feijão da segunda safra (plantio em janeiro e fevereiro) foi de 58.085 ha para uma produção de 101.940 t, seguida pelo feijão de inverno irrigado (plantio de abril a junho), que foi de 28.340 ha para uma produção de 68.988 t e a área com o feijão da seca final foi de 18.443 ha para uma produção de 19.599 t. Portanto, verifica-se que, no caso do feijão de inverno, a produtividade com irrigação é de cerca de $2.434 \mathrm{~kg} / \mathrm{ha}\left(41,06 \mathrm{sc} \mathrm{ha}^{-1}\right)$, enquanto na condição sem irrigação a produtividade cai para apenas $1.062 \mathrm{~kg} / \mathrm{ha}\left(17,70 \mathrm{sc} \mathrm{ha}^{-1}\right)$.

Dados do Instituto de Economia Agrícola - IEA (2008), na safra de 2007/2008, revelam que o cultivo de feijão de inverno sem irrigação produziu um total de 271 mil sacas de grãos, o que correspondeu a 6\% do total produzido. Cerca de 64 mil sacas, ou seja, 23\% foram produzidas nos municípios de atuação do Escritório de Desenvolvimento Rural (EDR) de Andradina, região oeste do Estado de São Paulo, destacando-se como o primeiro nesta modalidade de cultivo. Nesta época, a região apresenta ausência de geadas e temperaturas amenas, dificultando a ocorrência de pragas e doenças, o que favorece a qualidade do grão, com produtividade relativamente elevada. Os municípios mais representativos do EDR são: Ilha Solteira com 41,97\%, Andradina com 19,43\%, Pereira Barreto com 10,40\%, Murutinga do Sul com 9,32\% e Guaraçaí com 6,21\%, além de outros municípios que contribuem com percentuais menores, como Nova Independência, Lavínia e Mirandópolis.

BARROS et al. (2001) verificaram que os preços do feijão foram os que tiveram maiores oscilações anuais no período de 1975 a 2000. Vários fatores contribuem para isso, sendo um dos principais o fato de o produto apresentar demanda inelástica, em decorrência da limitação individual de seu consumo. Essa característica favorece a queda acentuada dos preços quando existir excesso do produto no mercado. Numa situação contrária, uma acentuada elevação ocorre no caso de quebras de safras. Isso ocorre pela falta de estoques internacionais suficientes e ainda pela rápida perda de qualidade do produto que impede a formação de estoques reguladores internamente.

O baixo uso de tecnologia e a fragilidade agronômica da lavoura, que não resiste bem à seca, ao excesso de chuvas e ainda é facilmente acometida por pragas e doenças, provocavam frustrações frequentes de safra, que resultavam em disparadas de preços seguidas de superofertas na safra seguinte. Esse excesso deprimia os preços e desestimulava novamente os produtores. $\mathrm{O}$ comportamento típico da produção e a possibilidade de produção de feijão em todos os Estados, em várias épocas do ano, começaram a despertar o interesse de outro perfil de produtores, que entraram na atividade com um sistema produtivo mais tecnificado. Conforme PESSOA (2007), os produtores de feijão podem ser classificados em dois grupos: os pequenos, que ainda usam baixa tecnologia e têm sua receita associada às condições climáticas, concentrados na produção das águas (primeira safra); e um segundo grupo, que usa produção mais tecnificada, com alta produtividade, plantio irrigado frequentemente por pivô central, concentrado nas safras da seca e do inverno (segunda e terceira safras).

GUERRA et al. (2000) relatam que o feijoeiro é, normalmente, a cultura anual de maior valor econômico e que, nas áreas irrigadas, tem condições de ser cultivado com alto nível tecnológico, pois a irrigação permite que o plantio seja feito em épocas adequadas e garante o fornecimento de água para que as plantas demonstrem seu potencial produtivo, podendo ultrapassar $4.000 \mathrm{~kg} \mathrm{ha}^{-1}$.

Os custos de produção do feijoeiro de inverno são relativamente elevados, sendo que, para a região de Pereira Barreto (SP), seu valor, subtraindo o custo da irrigação, está por volta de $\mathrm{R} \$ 3.500,00$ por hectare. Considerando-se a necessidade de se produzir nessa região com irrigação, a este valor será acrescido o custo da irrigação. Este pode elevar-se muito, se as condições da área plantada forem desfavoráveis, como, por exemplo, elevada distância até a fonte de água, elevado desnível geométrico da água e até mesmo se a área estiver longe de um ramal de energia elétrica em que o investimento na linha de alta tensão seja demasiadamente oneroso. 
O aspecto energético na irrigação é de grande importância, principalmente em épocas de crise. Em algumas regiões e em determinadas épocas do ano, pode ocorrer sobrecarga do sistema elétrico, causando falhas operacionais. Embora existam várias fontes de energia para acionamento de motores, a hidroeletricidade e o diesel são as mais utilizadas no Brasil e, portanto, mais enfatizadas nos trabalhos envolvendo custo de sistemas elevatórios (ZOCOLER, 2004).

TURCO et al. (2009) estimaram o consumo e o custo da energia elétrica na cultura do feijoeiro irrigado por pivô central de 3,32 ha, tendo como base o ensaio feito por LOPES et al. (2004), em que a cultura foi conduzida sob dois métodos de manejo da irrigação (tensiometria e balanço hídrico baseado na diferença entre evapotranspiração estimada pelo método do tanque "Classe A" e a chuva) e em dois sistemas de plantio (direto recém-implantado - 12 meses e convencional). Foi considerado o custo da energia elétrica para dois grupos tarifários: Grupo A e Grupo B. Para o Grupo A, foram determinados os dispêndios com a energia para a tarifa Estrutura Binômia Convencional e tarifa Horo-Sazonal (verde e/ou azul), além da tarifa especial para irrigantes no período noturno (Portaria DNAEE 105 de 3-4-1992, Resolução ANEEL 277 de 19-72000, e Resolução ANEEL 540 de 1ํ-10-2002). O preço da energia elétrica foi obtido junto à Companhia Paulista de Força e Luz - CPFL, e refere-se ao ano de 2006. Os autores concluíram que a tarifa Horo-Sazonal (verde e/ou azul), com desconto, foi a melhor opção, e que o manejo por tensiometria conduziu a menores consumos e custos de energia elétrica em relação ao balanço hídrico, não havendo diferença entre os sistemas de plantio. Os custos com consumo de energia elétrica na tarifa Horo-Sazonal foram: $\mathrm{R} \$ 171,84 \mathrm{ha}^{-1}$ - tensiometria e plantio direto; $\mathrm{R} \$ 170,28 \mathrm{ha}^{-1}$ tensiometria e plantio convencional; $\mathrm{R} \$ 214,39 \mathrm{ha}^{-1}$ balanço hídrico e plantio direto; e $\mathrm{R} \$ 214,39 \mathrm{ha}^{-1}$ balanço hídrico e plantio convencional, sendo as produtividades, respectivamente: $2.342,70 ; 2.397,50 ; 2.471,60$; e $2.630,60 \mathrm{~kg} \mathrm{ha}^{-1}$. Os autores não consideraram os custos fixos da irrigação.

Sendo assim, este trabalho teve o objetivo de simular os custos da irrigação de um sistema tipo pivô central de diferentes comprimentos de adutora e desníveis geométricos na produção do feijoeiro comum, na região de Ilha Solteira - SP, bem como a receita líquida obtida com a cultura, em cada configuração do sistema.

\section{MATERIAL E MÉTODOS}

As simulações de custos da irrigação foram realizadas utilizando-se do programa Otimização de Sistemas Elevatórios - OSE (ZOCOLER, 2003).

Considerou-se uma área irrigada de 103,58 hectares nas condições climáticas de Ilha Solteira, sendo dimensionado um sistema de irrigação para aplicação de uma lâmina diária máxima de $6,17 \mathrm{~mm}$ em 20 horas, proporcionando uma vazão de $319,5 \mathrm{~m}^{3} \mathrm{~h}^{-1}$. Esta lâmina foi calculada com base na evapotranspiração média de 9 anos (1999 a 2008), cujos dados climáticos foram obtidos junto à Área de Hidráulica e Irrigação, da Faculdade de Engenharia - Câmpus de Ilha Solteira/UNESP (http://www.agr.feis.unesp.br/ilhadados.php), que foi de 4,1 $\mathrm{mm}$, ocorrida no período de floração, cujo Kc é 1,28, considerando ainda uma eficiência de aplicação de $85 \%$.

Considerou-se, também, que a irrigação durante o ciclo da cultura ocorreu no período de 01/maio a 19/julho, perfazendo uma lâmina líquida total de $251 \mathrm{~mm}$, calculada com base na evapotranspiração potencial média da cultura. Para que esta lâmina líquida ocorresse, considerando uma eficiência de aplicação de $85 \%$, a lâmina total aplicada foi de $295,3 \mathrm{~mm}$. Sabendo-se que a vazão do sistema é $319,5 \mathrm{~m}^{3} \cdot \mathrm{h}^{-1}$, então foram necessários 958 horas de operação do sistema na cultura do feijoeiro, assumindo-se a ausência de chuva no período considerado.

Para a simulação dos custos da irrigação, alguns parâmetros do sistema foram considerados inalterados (constantes), como, por exemplo, a vazão e o tamanho da área irrigada, e a linha de alta tensão. Os outros parâmetros que sofreram variações foram os seguintes:

i) Desnível topográfico de bombeamento: 40; 50; 60; 70 e 80 metros; 
ii) Comprimento da tubulação de recalque: 1.000, 1.500, 2.000, 2.500 e 3.000 metros.

As demais constantes foram:

TABELA 1. Parâmetros fixos gerais de entrada no programa OSE. General fixed parameters of input in the OSE program.

Tubulação de sucção

Comprimento (m):

Material:

Rugosidade absoluta "e" fórmula universal (mm):

Aço Zincado

Expectativa de "Vida útil" desta tubulação (anos):

Dispêndio anual com manutenção e reparos

Dispêndio com os acessórios hidráulicos:

Dispêndio com a montagem da tubulação:

Tubulação de recalque

Material de composição dos tubos:

Aço Zincado

Rugosidade absoluta "e" da fórmula universal (mm):

0,2

Expectativa de "Vida útil" desta tubulação (anos):

Dispêndio anual com manutenção e reparos (\% do novo):

Dispêndio com os acessórios hidráulicos (\% do novo):

Dispêndio com a montagem da tubulação (\% da nova):

Dados dos componentes extras

Natureza do(s) componente(s):

Pivô central

Valor do(s) componente(s) novo(s) montado(s) (R\$):

$500.000,00$

Expectativa de "vida útil" (anos):

Valor de resgate após a "vida útil" (\% do valor novo):

Dispêndio anual com a manutenção e reparos (\% do valor novo)

1

Carga piezométrica necessária no ponto pivô (m) 50

Dados econômicos

Taxa anual de juros (\%):

Valor de resgate do sistema elevatório após "vida útil" (\% do novo):

Contudo, o sistema foi dimensionado, em cada variável proposta, numa configuração mais econômica entre cinco opções inseridas no Programa OSE, ou seja, utilizou-se a melhor configuração para a condição apresentada, o que significa que se houve, por exemplo, um acréscimo na extensão da tubulação de recalque, a configuração do sistema não foi alterada somente neste item, mas possivelmente os outros itens também o foram, como bomba hidráulica, motor elétrico, comando de partida, etc. Portanto, foram realizadas 25 simulações ( 5 desníveis versus 5 comprimentos da tubulação de recalque), e em cada simulação, 5 opções no programa OSE.

No caso da linha de alta tensão, considerou-se um investimento de $\mathrm{R} \$ 72.000,00$ para sua implantação, numa extensão de $4 \mathrm{~km}\left(\mathrm{R} \$ 18.000,00 \mathrm{~km}^{-1}\right.$ correspondente a um traçado-padrão).

A modalidade de tarifação de energia elétrica utilizada foi a horo-sazonal verde, aplicada ao subgrupo A4 com desconto especial para irrigantes, conforme a Resolução Normativa 207, de 9 de janeiro de 2006, da Agência Nacional de Energia Elétrica - ANEEL. Os preços das tarifas foram obtidos da Concessionária Elektro, praticados no ano de 2008, sendo: Demanda R\$11,01 $\mathrm{kW}^{-1} \mathrm{e}$ Consumo no período seco (maio a novembro) no horário fora da ponta (20h30 do dia anterior até $17 \mathrm{~h} 30$ do dia) $\mathrm{R} \$ 116,82 \mathrm{MWh}^{-1}$. 
Sendo assim, o investimento inicial médio para a aquisição dos equipamentos, montagem e construção das estruturas anexas foi $\mathrm{R} \$ 1.056 .284,00$ numa configuração média, ou seja, $2.000 \mathrm{~m}$ de comprimento da tubulação de recalque, $60 \mathrm{~m}$ de desnível topográfico e $4.000 \mathrm{~m}$ de linha de alta tensão.

Os demais preços de equipamentos (tubos, bombas, motores elétricos, comandos de partida, linha de alta tensão, sistema pivô central) e serviços também foram obtidos no mercado durante o segundo semestre do ano de 2008.

No presente trabalho, foi considerada uma safra de inverno em que o sistema de irrigação operaria durante 958 horas, ou seja, $48 \%$ do tempo total de operação anual do sistema, assumido, portanto, igual a 2.000 horas. Sendo assim, a depreciação anual do sistema referente à cultura considerada também foi equivalente a este percentual.

O programa OSE considera como custo anual fixo (CAF) a somatória da depreciação anual, calculada pelo método do fundo de formação de capital (FRIZZONE et al., 2005), e remuneração do capital investido nos equipamentos, instalações e serviços. O custo anual de manutenção e reparos (CAMR) considera os dispêndios ocorridos no ano, necessários para manter o sistema de irrigação em condições normais de operação. Custo anual de bombeamento (CAB) considera a soma do faturamento anual da demanda, faturamento anual do consumo e ajuste anual do fator de potência, sendo este nulo quando o sistema de bombeamento possui um banco de capacitores para sua correção até o mínimo estabelecido pela concessionária de energia elétrica.

Os insumos e serviços utilizados na produção do feijoeiro, bem como seus custos foram obtidos com RAPASSI et al. (2008) e adaptados para Ilha Solteira - SP. Para uma expectativa de produtividade de $3.000 \mathrm{~kg} \mathrm{ha}^{-1}$ (50 sacas por ha), o custo de produção do feijoeiro, excetuando-se os custos da irrigação que são fontes de variação no trabalho, obteve-se o valor de $\mathrm{R} \$ 3.587,76 \mathrm{ha}^{-1}$.

Considerando a produtividade de $3.000 \mathrm{~kg} \mathrm{ha}^{-1}$ (50 sacas por hectare), custo de produção de $\mathrm{R} \$ 3.587,76 \mathrm{ha}^{-1}$, preço médio da saca do feijão pago ao produtor no mês de agosto de 2008 ( $\mathrm{R} \$ 163,44$, Instituto de Economia Agrícola - IEA) e, também, o preço médio histórico real do feijão no mês de agosto, durante o período de 2001 a 2008, foram realizados os cálculos da receita líquida com a cultura nas diferentes configurações do sistema de irrigação simuladas no trabalho. Também foram calculados os preços de equilíbrio (ou nivelamento) como o preço mínimo necessário para cobrir os custos de produção nas diferentes configurações do sistema de irrigação.

$\mathrm{Na}$ obtenção do preço médio real do feijão durante o período de agosto de 2001 a agosto de 2008, foi utilizado o IGP-M divulgado pela Fundação Getúlio Vargas. Foram considerados os preços médios nominais da saca do feijão recebido pelos produtores nos meses de agosto de 2001 a 2008, segundo o Instituto de Economia Agrícola - IEA. O valor médio real obtido foi $\mathrm{R} \$ 108,31 \mathrm{sc}^{-1}$.

\section{RESULTADOS E DISCUSSÃO}

Na Tabela 2, apresenta-se, para os desníveis topográficos de bombeamento e comprimentos da tubulação de recalque, o custo anual da irrigação, o custo total de produção, a porcentagem de participação da irrigação no custo de produção, o preço de equilíbrio por saca de feijão, a receita líquida em relação ao preço do feijão de inverno recebido pelo produtor em agosto de 2008 e a receita líquida histórica para as condições climáticas de Ilha Solteira - SP.

Em relação à Tabela 2, verifica-se que o custo anual da irrigação variou de $\mathrm{R} \$ 624,60 \mathrm{ha}^{-1} \mathrm{a}$ $\mathrm{R} \$$ 980,51 ha $\mathrm{ha}^{-1}$, entre as condições extremas, ou seja, do menor desnível topográfico $(40 \mathrm{~m}) \mathrm{e}$ comprimento da tubulação de recalque $(2.000 \mathrm{~m})$ ao maior desnível $(80 \mathrm{~m})$ e comprimento $(3.000 \mathrm{~m})$. Isto fez com que a participação da irrigação no custo de produção variasse de 14,8 a 21,5\%. Entre tais extremos, haveria uma perda de receita líquida de $\mathrm{R} \$ 355,91 \mathrm{ha}^{-1}$, que representaria - 9\% no caso do preço pago ao produtor no mês de agosto de 2008 e - 29,6\% no caso do preço histórico. Com isso, o preço de equilíbrio teria de subir de $\mathrm{R} \$ 84,25 \mathrm{sc}^{-1}$ para 
$\mathrm{R} \$ 91,37 \mathrm{sc}^{-1}$, representando a variação de $8,5 \%$, ou seja, para a produtividade esperada de $50 \mathrm{sc} \mathrm{ha}^{-1}$ no primeiro caso, o produtor cobriria seus custos de produção se o preço fosse $\mathrm{R} \$ 84,25 \mathrm{sc}^{-1}$ e, no segundo, se o preço fosse $\mathrm{R} \$ 91,37 \mathrm{sc}^{-1}$. Contudo, com os preços praticados em agosto de 2008 ou o preço histórico médio (mês de agosto no período de 2001 a 2008), em todas as configurações do sistema de irrigação, seria viável a cultura do feijoeiro, sendo até mesmo bastante atraente, proporcionando rendas líquidas de até $\mathrm{R} \$ 3.959,64 \mathrm{ha}^{-1}$ e $\mathrm{R} \$ 1.203,14 \mathrm{ha}^{-1}$ nos preços de agosto de 2008 e histórico médio, respectivamente. Por outro lado, deve-se alertar que, em todos os casos, o preço mínimo da saca de feijão para cobrir os custos de produção foram superiores ao preço mínimo oficial de $\mathrm{R} \$ 80,00 \mathrm{sc}^{-1}$, válido para o período estudado.

TABELA 2. Custo anual da irrigação (CAI/ha, em $\mathrm{R} \$$ ), custo de produção (CP/ha, em $\mathrm{R} \$$ ), participação da irrigação no custo de produção (Irrig., em \%), preço de equilíbrio por saca de feijão (PE/sc, em R\$), receita líquida (RL/ha, em R\$, agosto/2008) e receita líquida histórica (RLH/ha, em $\mathrm{R} \$$, agosto/2001 a agosto/2008), em função do comprimento da adutora (CA, em metros) e desnível topográfico (DT, em metros). Annual cost of irrigation (CAI/ha, in $\mathrm{R} \$)$, production cost $(\mathrm{CP} / \mathrm{ha}$ in $\mathrm{R} \$)$, irrigation participation in the production cost (Irrig. in \%), equilibrium price per bag of beans (PE/sc in $\mathrm{R} \$$ ), net income ( $\mathrm{RL} / \mathrm{ha}$ in $\mathrm{R} \$$, August/2008) and historical net income (RLH / ha in R\$, August 2001 to August 2008) due to the length of the pipeline (CA, in meters) and declivity (DT, in meters).

\begin{tabular}{cccccccc}
\hline DT & CA & CAI/ha & CP/ha & Irrig & PE/sc & RL/ha & RLH/ha \\
\hline 40 & 1000 & 624,60 & 4212,36 & 14,8 & 84,25 & 3959,64 & 1203,14 \\
40 & 1500 & 684,51 & 4272,27 & 16,0 & 85,45 & 3899,73 & 1143,23 \\
40 & 2000 & 741,24 & 4329,00 & 17,1 & 86,58 & 3843,00 & 1086,50 \\
40 & 2500 & 806,97 & 4394,73 & 18,4 & 87,89 & 3777,27 & 1020,77 \\
40 & 3000 & 865,70 & 4453,46 & 19,4 & 89,07 & 3718,54 & 962,04 \\
\hline 50 & 1000 & 650,74 & 4238,50 & 15,4 & 84,77 & 3933,50 & 1177,00 \\
50 & 1500 & 711,22 & 4298,98 & 16,5 & 85,98 & 3873,02 & 1116,52 \\
50 & 2000 & 768,38 & 4356,14 & 17,6 & 87,12 & 3815,86 & 1059,36 \\
50 & 2500 & 834,84 & 4422,60 & 18,9 & 88,45 & 3749,40 & 992,90 \\
50 & 3000 & 893,54 & 4481,30 & 19,9 & 89,63 & 3690,70 & 934,20 \\
\hline 60 & 1000 & 678,93 & 4266,69 & 15,9 & 85,33 & 3905,31 & 1148,81 \\
60 & 1500 & 735,82 & 4323,58 & 17,0 & 86,47 & 3848,42 & 1091,92 \\
60 & 2000 & 810,03 & 4397,79 & 18,4 & 87,96 & 3774,21 & 1017,71 \\
60 & 2500 & 860,91 & 4448,67 & 19,4 & 88,97 & 3723,33 & 966,83 \\
60 & 3000 & 930,34 & 4518,10 & 20,6 & 90,36 & 3653,90 & 897,40 \\
\hline 70 & 1000 & 708,48 & 4296,24 & 16,5 & 85,92 & 3875,76 & 1119,26 \\
70 & 1500 & 762,97 & 4350,73 & 17,5 & 87,01 & 3821,27 & 1064,77 \\
70 & 2000 & 820,14 & 4407,90 & 18,6 & 88,16 & 3764,10 & 1007,60 \\
70 & 2500 & 921,17 & 4508,93 & 20,4 & 90,18 & 3663,07 & 906,57 \\
70 & 3000 & 952,60 & 4540,36 & 21,0 & 90,81 & 3631,64 & 875,14 \\
\hline 80 & 1000 & 740,48 & 4328,24 & 17,1 & 86,56 & 3843,76 & 1087,26 \\
80 & 1500 & 814,96 & 4402,72 & 18,5 & 88,05 & 3769,28 & 1012,78 \\
80 & 2000 & 865,13 & 4452,89 & 19,4 & 89,06 & 3719,11 & 962,61 \\
80 & 2500 & 926,73 & 4514,49 & 20,5 & 90,29 & 3657,51 & 901,01 \\
80 & 3000 & 980,51 & 4568,27 & 21,5 & 91,37 & 3603,73 & 847,23 \\
\hline & & & & & & & \\
\hline
\end{tabular}


Isolando-se a fonte de variação de desnível topográfico da Tabela 2, obtém-se, em média, um acréscimo de $\mathrm{R} \$ 30,66 \mathrm{ha}^{-1}$ no custo anual da irrigação e, portanto, também no custo de produção da cultura para cada $10 \mathrm{~m}$ de acréscimo no desnível topográfico de bombeamento. Ou seja, a participação da irrigação no custo de produção eleva-se $0,57 \%$ a cada $10 \mathrm{~m}$ de elevação do terreno em relação à fonte de água. Este percentual foi relativamente baixo neste trabalho devido à não necessidade de se aumentar em muito a potência do sistema de bombeamento entre as situações extremas $(40$ e $80 \mathrm{~m})$ e, também, devido à maior participação do custo fixo (especialmente o proporcionado pela depreciação do sistema pivô central) em relação ao custo de bombeamento no custo da irrigação. Com isso, o impacto da elevação do desnível topográfico no preço de equilíbrio também foi pequeno, ou seja, $\mathrm{R} \$ 0,61 \mathrm{sc}^{-1}$ para cada $10 \mathrm{~m}$.

Isolando-se a fonte de variação do comprimento da tubulação de recalque da Tabela 2, obtémse, em média, o acréscimo de $\mathrm{R} \$ 61,78 \mathrm{ha}^{-1}$ no custo anual da irrigação e, portanto, também no custo de produção da cultura para cada $500 \mathrm{~m}$ de acréscimo na extensão desta tubulação, representando o acréscimo na participação da irrigação, no custo de produção, em 1,15\%. Com isso, o impacto da elevação da extensão da tubulação de recalque no preço de equilíbrio foi $\mathrm{R} \$ 1,24 \mathrm{sc}^{-1}$ para cada $500 \mathrm{~m}$. Devido à maior amplitude de variação do comprimento da tubulação de recalque $(500 \mathrm{~m})$ em relação ao desnível topográfico de bombeamento $(10 \mathrm{~m})$, avaliada neste trabalho, e somente devido a isso, o efeito da extensão da tubulação de recalque foi maior sobre os custos da irrigação que o efeito do desnível topográfico. Se fosse considerada, também, a variação de $10 \mathrm{~m}$ na extensão da tubulação de recalque, então o efeito do desnível seria muito maior, como é esperado. Em números, o acréscimo no custo anual da irrigação e, portanto, também no custo de produção da cultura seria $\mathrm{R} \$ 1,24 \mathrm{ha}^{-1}$, representando um acréscimo na participação da irrigação no custo de produção em $0,023 \%$.

\section{CONCLUSÕES}

A participação da irrigação no custo de produção do feijoeiro variou de 14,8 a 21,5\% entre as condições extremas, ou seja, do menor desnível topográfico $(40 \mathrm{~m})$ e comprimento da tubulação de recalque $(2.000 \mathrm{~m})$ ao maior desnível $(80 \mathrm{~m})$ e comprimento $(3.000 \mathrm{~m})$.

Entre tais extremos, haveria uma perda de receita líquida de $\mathrm{R} \$ 355,91 \mathrm{ha}^{-1}$.

Em média, para cada $10 \mathrm{~m}$ de acréscimo no desnível topográfico de bombeamento, o custo anual da irrigação/custo de produção da cultura aumentou $\mathrm{R} \$ 30,66 \mathrm{ha}^{-1}$.

Em média, para cada $500 \mathrm{~m}$ de acréscimo no comprimento da tubulação de recalque, o custo anual da irrigação/custo de produção da cultura aumentou $\mathrm{R} \$ 61,78 \mathrm{ha}^{-1}$.

Em todas as configurações do sistema de irrigação e com os preços praticados em agosto de 2008 ou o preço histórico médio, seria viável a cultura do feijoeiro, proporcionando rendas líquidas de até $\mathrm{R} \$ 3.959,64 \mathrm{ha}^{-1}$ e $\mathrm{R} \$ 1.203,14 \mathrm{ha}^{-1}$, respectivamente.

\section{REFERÊNCIAS}

BARROS, J. M. R.; RIZZIERI, J. A. B.; PICHETTI, P. Os efeitos da pesquisa agrícola para o consumidor. São Paulo: Fundação Instituto de Pesquisas Econômicas; EMBRAPA, 2001. 68 p.

CASER, D.V.; CAMARGO, A.M.P.; BUENO, C.R.F.; CAMARGO, F. P.; ÂNGELO, J.A.; OLIVETTI, M.P.A.; FRANCISCO, V.L.F.S. Previsões e estimativas das safras agrícolas do Estado de São Paulo, ano agrícola de2008/2009, $2^{\circ}$ levantamento, novembro de 2008. Informações Econômicas, São Paulo, v.38, n.3, p.134, nov. 2008.

CONAB. COMPANHIA NACIONAL DE ABASTECIMENTO. Acompanhamento da safra brasileira: grãos, sétimo levantamento, abril 2009. Companhia Nacional de Abastecimento. Brasília: CONAB, 2009. 39 p. 
CONAB. COMPANHIA NACIONAL DE ABASTECIMENTO. Último levantamento da safra brasileira de grãos. Disponível em: < http://www.conab.gov.br/conabweb/index.php?PAG=131> Acesso em: 25 jun. 2009.

FRIZZONE, J.A.; ANDRADE JR., A.S. ; SOUZA, J.L.M.; ZOCOLER, J.L. Planejamento de irrigação: análise de decisão de investimento. Brasília: Embrapa Informação Tecnológica, 2005. $626 \mathrm{p}$.

GUERRA, A.F.; SILVA, D.B.; RODRIGUES, G.C. Manejo de irrigação e fertilização nitrogenada para o feijoeiro na região dos cerrados. Pesquisa Agropecuária Brasileira, Brasília, v.35, n.6, p.1.229-1.236, 2000.

IEA. INSTITUTO DE ECONOMIA AGRÍCOLA. Análises e indicadores do agronegócio, v.3, n. 10,3 p.

LOPES, A.S.; PAVANI, L.C.; CORÁ, J.E.; ZANINI, J.R.; MIRANDA, H.A. Manejo da irrigação (tensiometria e balanço hídrico climatológico) para a cultura do feijoeiro em sistemas de cultivo direto e convencional. Revista Engenharia Agrícola, Jaboticabal, v.24, n.1, p.89-100, jan./abr. 2004.

MARTIN, N. B.; SERRA, R.; OLIVEIRA, M. D. M.; ÂNGELO, J. A.; OKAWA, H. Sistema "CUSTAGRI": sistema integrado de custos agropecuário. São Paulo: IEA/SAA, 1997. 75 p.

PESSÔA, A. S. M. Feijão. Disponível em:〈http://www.mre.gov.br/CDBRASIL/ITAMARATY/ WEB/port/economia/agric/producao/feijao/index.htm> Acesso em: 8 nov. 2008.

RAPASSI, R. M. A.; TARSITANO, M. A. A.; PROENÇA, E. R.; RIGONATO, L. C.; ALVES NETO, V. M. Análise econômica do cultivo de feijão de inverno irrigado no município de Pereira Barreto - SP: um estudo de caso. In: CONGRESSO NACIONAL DE PESQUISA DE FEIJÃO CONAFE , 9., 2008.

TURCO, J.E.P.; RIZZATTI, G.S.; PAVANI, L.C. Custo de energia elétrica em cultura do feijoeiro irrigado por pivô central, afetado pelo manejo da irrigação e sistemas de cultivo. Revista Engenharia Agrícola, Jaboticabal, v.29, n.2, p.311-320, abr.jun. 2009.

YOKOYAMA, L. P. Cultivo do feijoeiro comum. EMBRAPA Arroz e feijão, 2003. Disponível em: $<$ http://sistemasdeproducao.cnptia.embrapa.br/FontesHTML/Feijao/CultivodoFeijoeiro/ importancia.htm> Acesso em: 8 out. 2008

ZOCOLER, J.L. Modelo matemático para cálculo dos custos e otimização de sistemas de bombeamento. Ilha Solteira, 2003. 189 f. Tese (Livre-Docência) - Faculdade de Engenharia, Câmpus de Ilha Solteira, 2003.

ZOCOLER, J.L. et al. Modelo para determinação do diâmetro e velocidade de escoamento econômica em sistemas elevatórios de água. In: CONGRESSO TEMÁTICO DE DINÂMICA E CONTROLE DA SOCIEDADE BRASILEIRA DE MATEMÁTICA APLICADA E COMPUTACIONAL. Ilha Solteira, UNESP, 2004. 